\title{
Structures and thermodynamic phase transitions for oxygen and silver oxide phases on $\operatorname{Ag}\left\{\begin{array}{lll}1 & 1 & 1\end{array}\right\}$
}

\author{
A. Michaelides ${ }^{\text {a }}$, M.-L. Bocquet ${ }^{\text {b }}$, P. Sautet ${ }^{\text {b }}$, A. Alavi ${ }^{\text {a }}$, D.A. King ${ }^{\text {a,* }}$ \\ a Department of Chemistry, University of Cambridge, Lensfield Road, Cambridge CB2 1EW, UK \\ ${ }^{\mathrm{b}}$ Institut de Recherches sur la Catalyse, CNRS, 2 av. A. Einstein, 69626 Villeurbanne and Laboratoire de Chimie Théorique et des \\ Matériaux hybrides, Ecole Normale Supérieure, Lyon, France
}

Received 27 June 2002; in final form 14 October 2002

\begin{abstract}
With density functional theory, we have examined oxygen adsorption at surface and subsurface sites of $\operatorname{Ag}\{111\}$. The microscopic structure of $\mathrm{Ag}$ oxide epitaxed to $\operatorname{Ag}\{111\}$ has also been determined. In agreement with a recent scanning tunneling microscopy study, non-stoichiometric oxide growth is favoured over the previously assumed stoichiometric growth. An ab initio phase diagram for $\mathrm{O}$ on $\mathrm{Ag}\left\{\begin{array}{lll}1 & 1 & 1\end{array}\right\}$ has been constructed from the adsorption free energy of the various $\mathrm{O}$ and $\mathrm{Ag}$ oxide phases. The key finding is that under real conditions for ethylene epoxidation the active catalyst is likely to be non-stoichiometric Ag oxide.
\end{abstract}

(C) 2002 Elsevier Science B.V. All rights reserved.

Silver is a uniquely efficient catalyst for the partial oxidation of ethylene to ethylene epoxide. A starting point in the understanding of the epoxidation mechanism is to determine the microscopic structure of the catalytically active $\mathrm{O} / \mathrm{Ag}$ system. Despite receiving considerable attention, an atomic level understanding of the $\mathrm{O}$ covered $\mathrm{Ag}$ surface, especially at finite temperatures and pressures, remains elusive. Here we use density functional theory (DFT) to perform a thorough investigation of $\mathrm{O}$ as well as $\mathrm{Ag}$ oxide adsorption on $\operatorname{Ag}\{111\}$. Through the application of thermodynamics to our ab initio calculations we at-

\footnotetext{
${ }^{*}$ Corresponding author. Fax: +44-01223-762829.

E-mail address: daksec@ch.cam.ac.uk (D.A. King).
}

tempt to bridge the 'pressure and materials' gaps and make predictions about the active phase of Ag under typical catalytic conditions for epoxidation.

Numerous ultra-high vacuum (UHV) studies of the $\mathrm{O} / \mathrm{Ag}\{1111\}$ adsorption system have been performed. Of direct relevance to the present study was the 1974 observation by Rovida et al. [1] that a $(4 \times 4)$ LEED superstructure forms upon exposure of $\mathrm{O}$ to $\operatorname{Ag}\{111\}$. The $(4 \times 4)$ superstructure, which is stable in temperature programmed desorption (TPD) experiments to ca. $590 \mathrm{~K}$, has now become a characteristic of $\mathrm{O}$ on $\operatorname{Ag}\left\{\begin{array}{lll}1 & 1 & 1\end{array}\right\}$ [2-4]. The microscopic structure of this reconstruction is still, however, not clear. Originally the $(4 \times 4)$ pattern was interpreted in terms of the growth of a $\{111\}$ orientated trilayer of $\mathrm{Ag}_{2} \mathrm{O}$ epitaxed to the $\mathrm{Ag}\left\{\begin{array}{lll}1 & 1 & 1\end{array}\right\}$ surface [1]. Based on a coverage deter- 
mination of $0.41 \pm 10 \%$ of a monolayer (ML), Campbell proposed that this trilayer consisted of a plane of $\mathrm{Ag}$ between two planes of oxygens [2]. Various modifications of this original model have been proposed [4,5]. Notably, however, until the recent scanning tunneling microscopy (STM) study of Carlisle et al. [6], they all assumed a stoichiometric $\mathrm{Ag}_{2} \mathrm{O}$ overlayer. Under the STM the $(4 \times 4)$ superstructure imaged as a honeycomb of bright bumps, which were assigned to metallic $\mathrm{Ag}$ atoms by comparison with theoretical STM images. An $\mathrm{O}-\mathrm{Ag}-\mathrm{O}$ oxide ring then in turn surrounds each metallic Ag ad-atom. The resulting structural model for the epitaxed Ag oxide was similar to that suggested by Campbell except that an $\mathrm{Ag}$ atom was missing in the center of every third $\mathrm{O}-\mathrm{Ag}-\mathrm{O}$ ring, reducing the stoichiometry to $\operatorname{Ag}_{1.8} \mathrm{O}$. Upon heating for several minutes (10-45 $\mathrm{min})$ at $490 \mathrm{~K}$ the $\mathrm{Ag}$ oxide decomposes into a second, novel phase of $\mathrm{O}$ [7]. This phase, with a much lower coverage $(0.05 \pm 0.02 \mathrm{ML})$, consists of isolated chemisorbed $\mathrm{O}$ atoms on unreconstructed $\mathrm{Ag}\left\{\begin{array}{lll}1 & 1 & 1\end{array}\right\}$ terraces. The oxygen atoms imaged as depressions, $9 \AA$ in diameter, and mainly because of their large size it was suggested that they might be subsurface $\mathrm{O}$ atoms.

This work is motivated by several important issues that remain unresolved. Firstly, the precise atomic structure and stoichiometry of the $(4 \times 4)$ oxide reconstruction is not known. Secondly, it is not known if the recently identified low coverage phase of isolated $\mathrm{O}$ atoms consists of surface or subsurface $\mathrm{O}$ atoms. The third, and arguably the key issue, which we aim to resolve is what $\mathrm{O}$ phase is present under typical epoxidation conditions (10-20 atm, 550 K) [8]. To these ends we have performed DFT calculations for $\mathrm{O}$ and $\mathrm{Ag}$ oxide adsorption on $\operatorname{Ag}\left\{\begin{array}{lll}1 & 1 & 1\end{array}\right\}$. By calculating the Gibbs free energy of adsorption of the various chemisorbed $\mathrm{O}$ and oxide systems, a phase diagram for the $\mathrm{O} / \mathrm{Ag}\left\{\begin{array}{lll}1 & 1 & 1\end{array}\right\}$ system has been constructed from which the relative stability of the various $\mathrm{O}$ and oxide phases can be estimated.

Calculations were performed within the planewave pseudopotential formalism of DFT. Two codes; namely VASP [9-11] and CASTEP [12] were used. These codes utilise ultra-soft pseudopotentials and the Perdew Wang (PW91) general- ised gradient approximation. Almost all systems have been examined with both codes and this study represents the first direct comparison of these two widely distributed codes. Both sets of results are provided and on the whole the comparison in terms of structure and energy is good. The supercell approach is used to describe the $\mathrm{O} /$ $\mathrm{Ag}$ surfaces, with each repeat unit containing a slab of $4 \mathrm{Ag}$ layers separated by a vacuum region of $>14 \AA$. To model oxygen adsorption at different coverages $\mathrm{p}(2 \times 2)(0.25 \mathrm{ML}), \mathrm{p}(3 \times 3)(0.11 \mathrm{ML})$, $\mathrm{p}(4 \times 4)(0.06 \mathrm{ML})$, and $\mathrm{p}(5 \times 5)(0.04 \mathrm{ML})$ unit cells were considered. The $(4 \times 4)$ silver oxide overlayers were modeled in $\mathrm{p}(4 \times 4)$ unit cells with an $\mathrm{Ag}$ oxide trilayer adsorbed on top of the four layer Ag slab. $K$-point sampling equivalent to at least 64 symmetric points in the Brillouin Zone of a $(1 \times 1)$ cell were used throughout. During all structure optimisations the $\mathrm{Ag}$ atoms of the lower two layers were held fixed, and the remaining atoms fully optimised. Clearly some of the systems investigated in this study are large and have thus required considerable computational resources.

We consider first the low coverage $(0.05 \pm 0.02$ ML) phase of $\mathrm{O}$ on $\operatorname{Ag}\left\{\begin{array}{lll}1 & 1 & 1\end{array}\right\}$. This phase consists of isolated $\mathrm{O}$ atoms believed to be adsorbed at subsurface octahedral $\left(\mathrm{O}_{\mathrm{h}}\right)$ sites (Fig. 1) [7]. To address this issue we have performed DFT calculations for $\mathrm{O}$ adsorption at the on-surface (fcc, hcp, bridge and atop) and subsurface $\left(\mathrm{O}_{\mathrm{h}}\right.$ and tetrahedral $\left(\mathrm{T}_{\mathrm{d}}\right)$ ) sites of $\mathrm{Ag}\{111\}$ at coverages of 0.06 and $0.25 \mathrm{ML}$. These calculations reveal that the most stable surface site is the fcc threefold hollow site and that the most stable subsurface site is the $\mathrm{O}_{\mathrm{h}}$ site. Additional calculations for $\mathrm{O}$ adsorption at the fcc and $\mathrm{O}_{\mathrm{h}}$ sites at 0.04 and 0.11 ML were subsequently performed and thus a wide coverage range, straddling the reported experimental value of $0.05 \mathrm{ML}$, was examined. The geometry of $\mathrm{O}$ at the fcc and $\mathrm{O}_{\mathrm{h}}$ sites is displayed in Fig. 1 and detailed structural parameters and adsorption energies at two selected coverages given in Table 1. It can be seen from Table 1 that the results from both codes, both in terms of structures and energies, are similar. Small differences exist but we believe that these mainly originate from the slightly different lattice constants used with each code. The theoretical lattice constant 

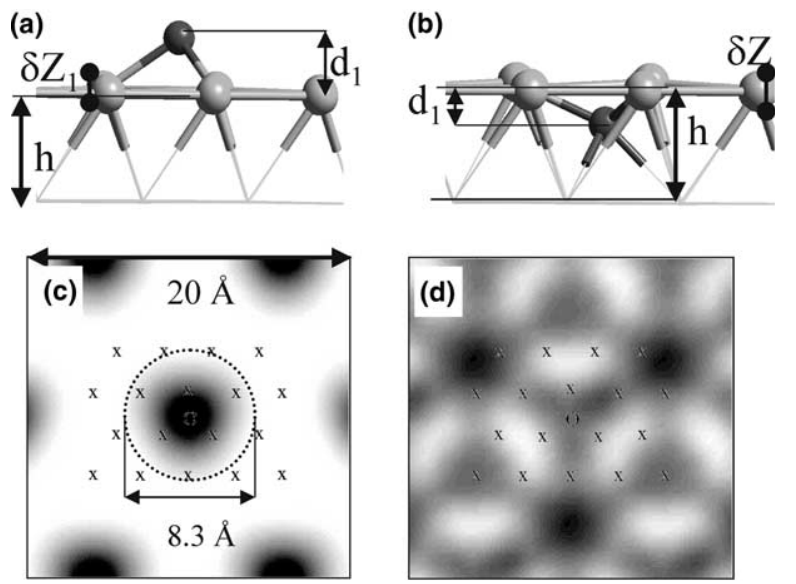

Fig. 1. (a)-(b) Side views of O (dark grey) adsorption at the fcc (a) and subsurface octahedral (b) sites of Ag $\{111\}$ (light grey). (c)-(d) Plan views of STM topographic simulations of $\mathrm{O}$ adsorption at the fcc (c) and subsurface octahedral (d) sites. In (c)-(d) the tunneling parameters are identical to the reported experimental values $(V=100 \mathrm{mV}, I=1 \mathrm{nA}$, W tip) and $\mathrm{O}$ is located at the centre of each image. The labels $(\times)$ indicate the registry of $\left\{\begin{array}{lll}1 & 1 & 1\end{array}\right\}$ silver substrate. The image corrugations are 0.2 and $0.02 \AA$ for the fcc and subsurface sites, respectively.

Table 1

Optimised geometrical parameters $(\AA)$ and adsorption energies $(\mathrm{eV})$ relative to $1 / 2 \mathrm{O}_{2}$ for $\mathrm{O}$ at the fcc surface and octahedral subsurface sites of $\operatorname{Ag}\{111\}$ at 0.25 and 0.06 ML. All labels are defined in Fig. 1

\begin{tabular}{|c|c|c|c|c|c|c|c|c|}
\hline & \multicolumn{2}{|c|}{ Surf fcc $0.25 \mathrm{ML}$} & \multicolumn{2}{|c|}{ Surf fcc $0.06 \mathrm{ML}$} & \multicolumn{2}{|c|}{ Sub $\mathrm{O}_{\mathrm{h}} 0.25 \mathrm{ML}$} & \multicolumn{2}{|c|}{ Sub $\mathrm{O}_{\mathrm{h}} 0.06 \mathrm{ML}$} \\
\hline & VASP & CASTEP & VASP & CASTEP & VASP & CASTEP & VASP & CASTEP \\
\hline $\mathrm{O}-\mathrm{Ag}$ & 2.14 & 2.14 & 2.16 & 2.15 & 2.20 & 2.21 & 2.19 & 2.18 \\
\hline $\mathrm{Ag}-\mathrm{Ag}$ & 3.08 & 3.03 & 3.14 & 3.01 & 3.17 & 3.14 & 3.48 & 3.40 \\
\hline$d_{1}$ & 1.21 & 1.25 & 1.22 & 1.32 & 1.14 & 1.18 & 0.76 & 0.83 \\
\hline$h$ & 2.38 & 2.34 & 2.39 & 2.38 & 2.70 & 2.69 & 2.44 & 2.42 \\
\hline$\delta Z_{1}$ & 0.12 & 0.10 & 0.08 & 0.06 & 0.32 & 0.36 & 0.14 & 0.20 \\
\hline$E_{\text {ad }}$ & -0.41 & -0.39 & -0.51 & -0.46 & 0.12 & 0.24 & 0.19 & 0.38 \\
\hline
\end{tabular}

predicted by VASP is $4.16 \AA$, which is similar to a DFT value of $4.20 \AA$ calculated by Scheffler and co-workers [13]. CASTEP, however, predicts a value of $4.11 \AA$ in better agreement with the experimental lattice constant $(4.09 \AA)$. Of particular interest it is apparent from Table 1 that both codes clearly indicate that in this low coverage regime the on-surface fcc site is energetically preferred, ca. $0.6 \mathrm{eV}$, to the subsurface $\mathrm{O}_{\mathrm{h}}$ site.

To fully resolve this issue STM simulations have been performed on our DFT optimised geometries for $\mathrm{O}$ adsorption at the fcc and $\mathrm{O}_{\mathrm{h}}$ sites. The STM simulations were performed with a Green's function-based scattering code that allows an atom-by-atom description of surface and tip apex. This method has been successfully applied by Carlisle et al. [6]. The simulated images, displayed in Fig. 1, support our assertion that the experimentally observed $\mathrm{O}$ atoms are indeed onsurface oxygens. Figs. $1 \mathrm{c}$ and $\mathrm{d}$ correspond to $\mathrm{O}$ adsorption at the fcc and $\mathrm{O}_{\mathrm{h}}$ sites, respectively. In Fig. 1c large depressions $8.3 \AA$ in diameter are centered on the $\mathrm{O}$ atoms. This image qualitatively and semi-quantitatively resembles the observed STM depression of Carlisle et al. [7]. The STM simulation for $\mathrm{O}$ at the subsurface $\mathrm{O}_{\mathrm{h}}$ site, however, shows only a very small spatial modulation of the contrast with the absolute minima located 
over oxygen-free threefold sites. Indeed the corrugation in this simulation is negligible $(0.02 \AA)$; exactly one order of magnitude less than the depth of the on-surface oxygen depression. From the combination of total energy and STM image calculations, we conclude therefore that $\mathrm{O}$ adsorption at low coverages on $\operatorname{Ag}\left\{\begin{array}{llll}1 & 1 & 1\end{array}\right\}$ occurs at on-surface fcc sites.

Moving to the investigation of Ag oxide adsorption on $\operatorname{Ag}\{111\}$, we now report the first accurate geometry determination. Structure optimisations were performed for a trilayer of $\mathrm{Ag}_{2} \mathrm{O}$ epitaxed on $\operatorname{Ag}\{111\}$ as well as a $\mathrm{Ag}$ deficient trilayer, equivalent to an oxide overlayer with a stoichiometry of $\operatorname{Ag}_{1.8} \mathrm{O}$. The optimised structures of each oxide overlayer are very similar and the only appreciable difference is the absence of a single chemisorbed $\mathrm{Ag}$ atom in the center of one of the $\mathrm{Ag}-\mathrm{O}-\mathrm{Ag}$ rings. The structure of the $\mathrm{Ag}$ deficient $\operatorname{Ag}_{1.8} \mathrm{O}$ overlayer is shown in Fig. 2 and a comprehensive list of structural parameters obtained from both CASTEP and VASP calculations is provided in Table 2. Again it can be seen that agreement between the two codes is good and any small discrepancies may be attributed to the different Ag lattice constants used. The nearest $\mathrm{Ag}-\mathrm{O}$ distances of the oxide film are close to those in the bulk oxide $(2.04 \AA)$. There is significant buckling within the trilayer of about $0.45 \AA$, as well as a $0.14 \AA$ A rumpling of the underlying $\operatorname{Ag}\left\{\begin{array}{lll}1 & 1 & 1\end{array}\right\}$ substrate (Fig. 2).

Having now determined with DFT numerous $\mathrm{O}$ atom adsorption phases as well as the two $\mathrm{Ag}$ oxide overlayers on $\operatorname{Ag}\left\{\begin{array}{lll}1 & 1 & 1\end{array}\right\}$ we now examine their relative stability as a function of temperature
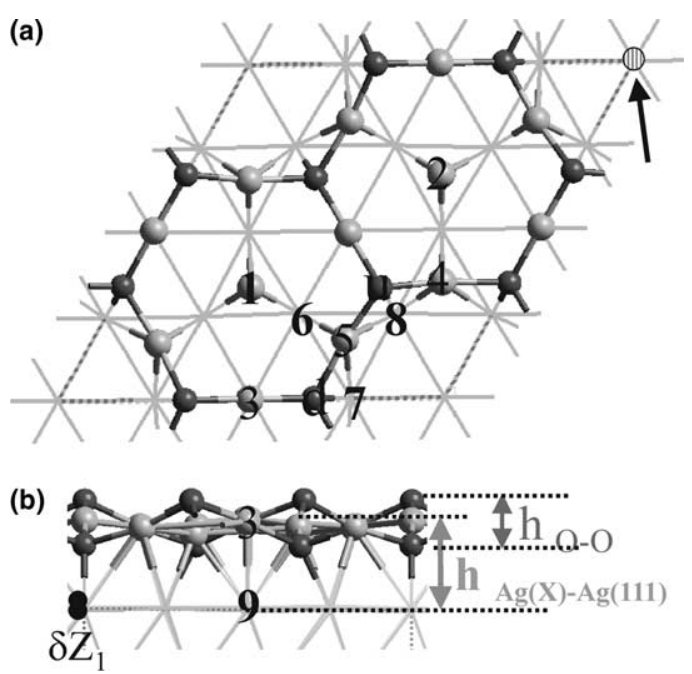

Fig. 2. Plan (a) and side (b) views of the structure of the $\mathrm{p}(4 \times 4) \operatorname{Ag}_{1.8} \mathrm{O}$ oxide overlayer on $\operatorname{Ag}\{111\}$. Grey sticks represent the Ag substrate. Grey (dark grey) balls depict Ag (O) atoms in the oxide overlayer. In (a) the arrow and the hatched circle mark the location of the additional $\mathrm{Ag}$ atom that is present in the $\mathrm{Ag}_{2} \mathrm{O}$ oxide overlayer.

and pressure. To do this we can equally compare their surface energies $(\gamma)[14,15]$ or their Gibbs' free energies of adsorption $(\Delta G)$. Here we opt for the latter because we are primarily interested in comparing the stability of structural overlayers that form upon the bare $\mathrm{Ag}$ surface rather than on comparing the energies for the overall formation of these surfaces. In fact when normalised by the same surface area $\gamma$ and $\Delta G$ are simply related by the surface energy of the clean $\operatorname{Ag}\left\{\begin{array}{lll}1 & 1 & 1\end{array}\right\}$ surface. The Gibbs' free energy of adsorption is

Table 2

Optimised geometrical parameters in $\AA$ for the $\mathrm{O} p(4 \times 4) \operatorname{Ag}_{1.8} \mathrm{O}$ oxide reconstruction on $\mathrm{Ag}\{111\}$. The structure and atomic labels of this phase are shown in Fig. 2

\begin{tabular}{llllll}
\hline & VASP & CASTEP & & VASP & CASTEP \\
\hline $\mathrm{Ag}(1)-\mathrm{Ag}(5)$ & 3.29 & 3.34 & $\mathrm{O}_{\mathrm{u}}-\mathrm{Ag}(8)$ & 3.47 & 3.52 \\
$\mathrm{Ag}(1)-\mathrm{Ag}(6)$ & 2.84 & 2.79 & $\mathrm{O}_{\mathrm{d}}-\mathrm{Ag}(7)$ & 2.32 & 2.33 \\
$\mathrm{Ag}(1)-\mathrm{Ag}(3)$ & 3.42 & 3.40 & $h_{\mathrm{Ag}(1)-\mathrm{Ag}(111)}$ & 2.35 & 2.23 \\
$\mathrm{Ag}(3)-\mathrm{Ag}(9)$ & 2.82 & 2.79 & $h_{\mathrm{Ag}(3)-\mathrm{Ag}(111)}$ & 2.77 & 2.76 \\
$\mathrm{Ag}(5)-\mathrm{Ag}(7)$ & 3.07 & 3.07 & $h_{\mathrm{Ag}(4)-\mathrm{Ag}(111)}$ & 2.57 & 2.57 \\
$\mathrm{Ag}(5)-\mathrm{O}_{\mathrm{u}}$ & 2.07 & 2.07 & $h_{\mathrm{O}_{\mathrm{u}}-\mathrm{O}_{\mathrm{d}}}$ & 1.40 & 1.44 \\
$\mathrm{Ag}(5)-\mathrm{O}_{\mathrm{d}}$ & 2.11 & 2.11 & $\delta Z_{1}$ & 0.14 & 0.13 \\
\hline
\end{tabular}




$$
\begin{aligned}
\Delta G(T, P)= & \frac{1}{A}[G(\mathrm{O} / \operatorname{Ag}\{111\})-G(\operatorname{Ag}\{111\}) \\
& \left.-N_{\mathrm{O}} \mu_{\mathrm{O}}(T, P)-N_{\mathrm{Ag}} \mu_{\mathrm{Ag}}(T, P)\right] .
\end{aligned}
$$

Here $G(\mathrm{O} / \mathrm{Ag}\{1111\})$ denotes the total Gibbs free energy of our $\mathrm{O}$ or oxide covered $\mathrm{Ag}$ surfaces. $G(\operatorname{Ag}\{1111\})$ is the total energy of the clean four layer $\operatorname{Ag}\{111\}$ slab. $\mu_{\mathrm{O}}$ is the chemical potential of $\mathrm{O}$ and $N_{\mathrm{O}}$ is the number of $\mathrm{O}$ atoms in the supercell. The final $\left(N_{\mathrm{Ag}} \mu_{\mathrm{Ag}}\right)$ term only comes into play for the Ag oxide systems, accounting for the additional $\mathrm{Ag}$ atoms present in the $\mathrm{Ag}$ oxide overlayers. For these two cases $N_{\mathrm{Ag}}$ is the number of (excess) $\mathrm{Ag}$ atoms in the $\mathrm{Ag}$ oxide overlayers and $\mu_{\mathrm{Ag}}$ is the chemical potential of these $\mathrm{Ag}$ atoms. $\Delta G(T, P)$ is normalised to energy per unit area by dividing through the surface area $A$ of our slab. To maintain a thermodynamic equilibrium we define the chemical potential of the excess $\mathrm{Ag}$ atoms in the oxide overlayers by that of the bulk crystal and is thus simply our DFT computed total energy of a bulk Ag atom. The chemical potential of $\mathrm{O}$ is referenced to oxygen molecules in the gaseous phase for which we use the ideal gas equation. It is well-known that the ideal gas equation suffers deficiencies at low temperatures and high pressures. Fortunately under the conditions we are primarily interested in (high temperatures and moderate pressures) it is a well-behaved approximation. With this approach we can now go beyond standard DFT calculations and investigate the temperature and pressure dependence of $\mu_{\mathrm{O}}$ and thus the temperature and pressure influence on the stability of the various oxygen and oxide phases. However, in the present study we have neglected temperature and pressure effects on the Gibbs free energy of our solid slabs, i.e., the Gibbs free energy appearing in eq. (1) is approximated by the total energy at zero temperature. This is justified because the corresponding corrections are small $[16,17]$ compared to the temperature and pressure dependence of the vapour contribution (which we include explicitly).

Figs. $3 a$ and $b$ show the Gibbs energy of adsorption as a function of temperature at typical UHV $\left(10^{-12} \mathrm{~atm}\right)$ and industrial epoxidation pressures (15 atm). The important conclusion we can immediately draw is that the silver deficient $\mathrm{Ag}_{1.8} \mathrm{O}$ oxide is more stable than the stoichiometric $\mathrm{Ag}_{2} \mathrm{O}$ oxide. Since both oxide phases contain the same number of $\mathrm{O}$ atoms, their relative stability is independent of temperature and pressure, with the silver deficient $\operatorname{Ag}_{1.8} \mathrm{O}$ oxide favoured by 0.74 and $0.46 \mathrm{eV}$ per $(4 \times 4)$ oxide unit cell with CASTEP and VASP, respectively. Thus there is a clear preference for non-stoichiometric $\operatorname{Ag}_{1.8} \mathrm{O}$ growth on $\mathrm{Ag}\left\{\begin{array}{lll}1 & 1 & 1\end{array}\right\}$. The reason for this preference is that the additional metallic $\mathrm{Ag}$ atom in the $\mathrm{Ag}_{2} \mathrm{O}$ overlayer would have sit at an unfavourable ontop site of the underlying $\operatorname{Ag}\left\{\begin{array}{lll}1 & 1 & 1\end{array}\right\}$ substrate.
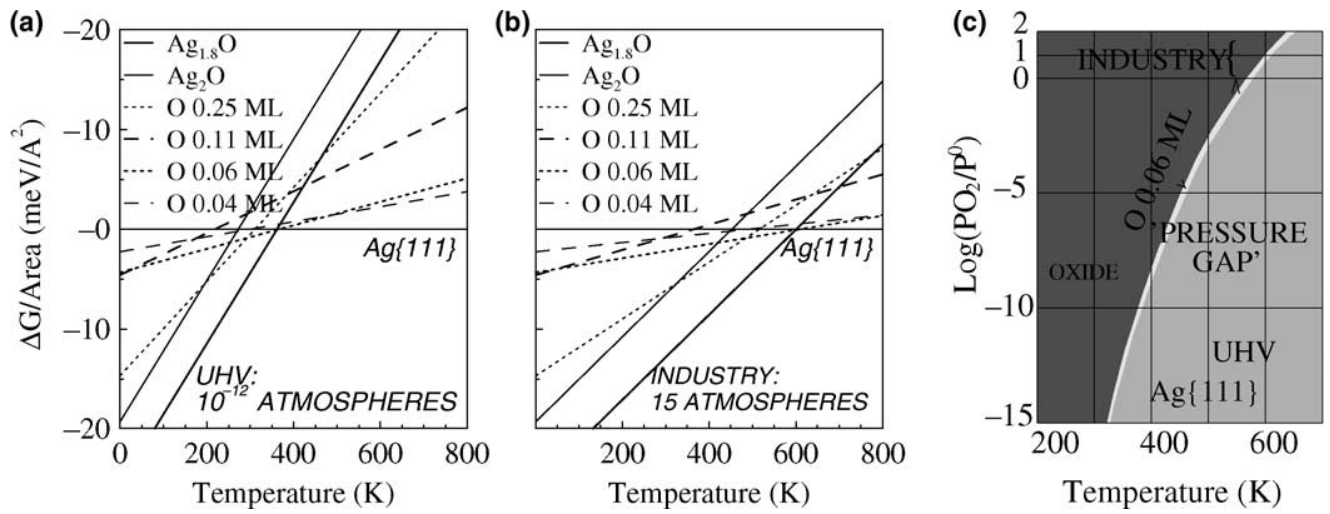

Fig. 3. Normalised Gibbs energy of adsorption against temperature at (a) $10^{-12}$ atm and (b) 15 atm, for various phases of $\mathrm{O}$ on $\operatorname{Ag}\left\{\begin{array}{lll}1 & 1 & 1\end{array}\right\}$. (c) A two-dimensional ab initio derived phase diagram for the $\mathrm{O} / \mathrm{Ag}\left\{\begin{array}{lll}1 & 1 & 1\end{array}\right\}$ adsorption system. For clarity in (a)-(c) only the CASTEP results are plotted. The VASP results yield strikingly similar plots with all thermodynamic crossings within $10 \mathrm{~K}$ of the CASTEP values. 
Examining next the effect of temperature on the relative stability of the various phases we see dramatic changes. At $U H V$ pressure (Fig. 3a), three distinct phases are stable. (1) At low temperatures up to $360 \mathrm{~K}$, the $\operatorname{Ag}_{1.8} \mathrm{O}$ phase is the most stable; (2) over the very short range between $360 \mathrm{~K}$ and $370 \mathrm{~K}$ the $0.06 \mathrm{ML} \mathrm{O}$ ad-atom phase is stable; and (3) above $370 \mathrm{~K}$ the clean $\operatorname{Ag}\left\{\begin{array}{lll}1 & 1 & 1\end{array}\right\}$ surface becomes thermodynamically stable. Moving to a typical pressure used under industrial epoxidation conditions, 15 atm (Fig. 3b), the same three phases are predicted. The thermodynamic transitions are, however shifted to higher temperatures by ca. $240 \mathrm{~K}$. Thus the oxide to $0.06 \mathrm{ML} \mathrm{O}$ ad-atom transition now occurs at $600 \mathrm{~K}$. The complete temperature and pressure dependence of the $\mathrm{O} / \mathrm{Ag}\left\{\begin{array}{lll}1 & 1 & 1\end{array}\right\}$ system within the pressure range $1 \times 10^{-15}$ to $100 \mathrm{~atm}$ and the temperature range 200 to $700 \mathrm{~K}$ is displayed in Fig. 3c. This is a twodimensional $\mathrm{ab}$ initio derived phase diagram that plots the most stable (equilibrium) phase at a particular $(\mathrm{P}, \mathrm{T})$ pair. Expanding on Figs. 3a and $\mathrm{b}$ it reveals that the only stable phases in the temperature and pressure regime investigated are the $\mathrm{Ag}_{1.8} \mathrm{O}$ oxide, the $0.06 \mathrm{ML} \mathrm{O}$ ad-atom and the clean $\operatorname{Ag}\{111\}$ surface. At no stage does the lower coverage $(0.04 \mathrm{ML})$ phase or any of the higher coverage $\mathrm{O}$ ad-atom $(0.11$ and $0.25 \mathrm{ML})$ phases become stable. The key insight, which can be gleaned from this figure, is that in the range of pressures and temperature at which industrial ethylene epoxidation is conducted the $\operatorname{Ag}_{1.8} \mathrm{O}$ oxide phase is thermodynamically the most stable. Indeed Figs. 3a-c point to a crucial pressure and materials gap for $\mathrm{Ag}$ oxidation catalysis: On raising the pressure, at a temperature of $550 \mathrm{~K}$, from UHV to industrial pressures the state of the $\mathrm{Ag}$ substrate is predicted to change from bare $\mathrm{Ag}\left\{\begin{array}{lll}1 & 1 & 1\}\end{array}\right.$ to $\operatorname{Ag}_{1.8} \mathrm{O}$ oxide.

Where comparison is possible, Fig. $3 \mathrm{c}$ is in satisfactory agreement with the recent experiments of Carlisle et al. [7], in which oxide decomposition was probed with the STM. It was found that when the oxide overlayer was heated slowly at $490 \mathrm{~K}$ (10-45 $\mathrm{min})$ in vacuo it began to decompose into the low coverage $(0.05 \mathrm{ML}) \mathrm{O}$ ad-atom phase. Although we have not attempted to model the precise two-phase system encountered experimen- tally it is clear that our phase diagram predicts the same qualitative behaviour. Considering finally the oxide decomposition temperatures of $490 \mathrm{~K}$ upon slow heating [7] and ca. $590 \mathrm{~K}$ [2] with rapid heating, as conducted in a TPD experiment. The implication from our calculations is that, for these processes, kinetic barriers exist that inhibit oxide decomposition until suitably high surface temperatures are achieved.

In conclusion, stable phases of $\mathrm{O}$ on $\mathrm{Ag}\left\{\begin{array}{lll}1 & 1 & 1\end{array}\right\}$ have been characterised with DFT. In addition $a b$ initio thermodynamics reveals that there is a significant pressure gap on moving from surface science to industrial conditions and that the active catalyst for ethylene epoxidation under industrial conditions is likely to be the silver deficient $\operatorname{Ag}_{1.8} \mathrm{O}$ oxide overlayer.

\section{Acknowledgements}

This work has been supported by EPSRC. MLB and PS thank IDRIS and CNRS for CPU time (Project 609).

\section{References}

[1] G. Rovida, F. Pratesi, M. Maglietta, E. Ferroni, Surf. Sci. 43 (1974) 230.

[2] C.T. Campbell, Surf. Sci. 157 (1985) 43.

[3] R.B. Grant, R.M. Lambert, Surf. Sci. 146 (1984) 256.

[4] V.I. Bukhtiyarov, V.V. Kaichev, P.I. Prosvirin, J. Chem. Phys. 111 (1999) 2169.

[5] S.R. Bare, K. Griffiths, W.N. Lennard, H.T. Tang, Surf. Sci. 342 (1995) 185.

[6] C.I. Carlisle, D.A. King, M.-L. Bocquet, J. Cerda, P. Sautet, Phys. Rev. Lett. 84 (2000) 3899.

[7] C.I. Carlisle, T. Fujimoto, W.S. Sim, D.A. King, Surf. Sci. $470(2000) 15$.

[8] J.M. Berty, in: B. Leach (Ed.), Ethylene Epoxide Synthesis, Applied Industrial Catalysis, vol. 1, Academic Press, 1983.

[9] G. Kresse, J. Hafner, Phys. Rev. B 47 (1993) 558.

[10] G. Kresse, J. Furthmuller, Comput. Mater. Sci. 6 (1996) 15.

[11] G. Kresse, J. Furthmuller, Phys. Rev. B 54 (1994) 11169.

[12] CASTEP 4.2 Academic Version, licensed under the UKCPMSI Agreement, 1999 M.C. Payne et al., Rev. Mod. Phys. 64 (1992) 1045.

[13] W.X. Li, C. Stampfl, M. Scheffler, Phys. Rev. B 65 (2002) 075407. 
[14] X.-G. Wang et al., Phys. Rev. Lett. 81 (1998) 1038.

[15] X.-G. Wang, A. Chaka, M. Scheffler, Phys. Rev. Lett. 84 (2000) 3650.
[16] J. Xie, S. de Gironcoli, S. Baroni, M. Scheffler, Phys. Rev. B 59 (1999) 970.

[17] K. Reuter, M. Scheffler, Phys. Rev. B 65 (2002) 035406. 